\title{
Building Energy Performance, Regulations and Certificates
}

\author{
PhD Candidate Ibrahim Can Korkut \\ This paper is the author's partial work of $\mathrm{PhD}$ dissertation
}

\begin{abstract}
Energy consumption, performance and efficiency are of vital importance for all countries. The world's growing population, depletion of traditional energy sources and the use of increasingly higher technology have made it necessary, if not compulsory, to take precautions and build standards to increase energy performance of buildings and appliances as buildings and their energy performance play a significant role in energy consumption. Efforts supported by regulations such as The European Union Energy Performance of Buildings Directory in the European Union enable energy saving precautions and measurements to be applicable and effective. Applying to standards to evaluate buildings' energy performances and ratings is becoming compulsory steps in today's standardoriented world as The European Union Energy Performance of Buildings Directory sets targets to increase building energy performance and reduce energy consumption. However, it is understandable that the processes of standardizations and regulations are progressive ones as people always demand higher living standards.
\end{abstract}

Keywords — building, certificate, energy performance, regulation.

\section{BUILDING ENERGY PERFORMANCE AND RATINGS}

$\mathrm{T}$ HE energy performance of a building is "the calculated or measured amount of energy needed to meet the energy demand associated with a typical use of the building, which includes, inter alia, energy used for heating, cooling, ventilation, hot water and lighting [1]. The same official journal referring to Directive 2002/91/EC of the European Parliament and of The Council provides the criteria stating that this amount shall be reflected in one or more numeric indicators which have been calculated, taking into account insulation, technical and installation characteristics, design and positioning in relation to climatic aspects, solar exposure and influence of neighboring structures, own-energy generation and other factors, including indoor climate, that influence the energy demand [1].

Thus, the energy performance of a building should be evaluated through some calculation to build necessary indicators and ratings. European Committee for Standardisation European Standard EN 15603 defines the criteria to assess building energy use and methodology to

Ibrahim Can Korkut is with the Department of Business Administration, Epoka University, Tirana, 1039 Albania estimate total energy rating of a building [2]. Naturally a lot of buildings use different types of energy sources and the cumulative energy use is calculated in variety of energy units. While calculating overall/cumulative energy use, three impacts of energy use as primary energy use, carbon dioxide emission and national energy policy parameter are taken into consideration. In some cases, energy costs are also used as an indicator. The energy rating of a building can be defined as "the evaluation of the energy performance of the building based on the weighted sum of the calculated or metered use of energy carriers" [3].

Basically there are two types of building energy ratings;

- The Calculated Rating: It is achieved through calculation and estimation of all energy sources delivered.

- The Measured/Operational Rating: It is achieved through measurement and estimation of all energy sources delivered. Since it is achieved through calculation, the calculated rating can vary depending on calculation methods, occupancy and climate zone. Three basic calculated rating types are design rating, asset rating and tailored rating. The design rating calculates the energy rating of a building at designing stage. The asset rating and the tailored rating are similar and both calculate the energy rating of a building after construction. The difference between them is that the asset rating calculates the energy rating of a building after construction with standard occupancy and climate data whereas the tailored rating does so with actual occupancy and climate data. Calculated ratings can be most beneficial when the building is new, big or/and multi-faceted, and when occupants of the building change often. This type energy rating can be achieved according to primary energy consumption or on-site energy use. Most European countries use calculated energy rating for new, small and non-public buildings while they use operational rating for "large and complex nonresidential buildings, and for the regular rating of public buildings" [4]. Calculated energy rating states how primary energy is used per unit floor area per year $\left(\mathrm{kWh} / \mathrm{m}^{2} / \mathrm{yr}\right)$. A sample Building Energy Rating (BER) chart is given below in Figure 1. 


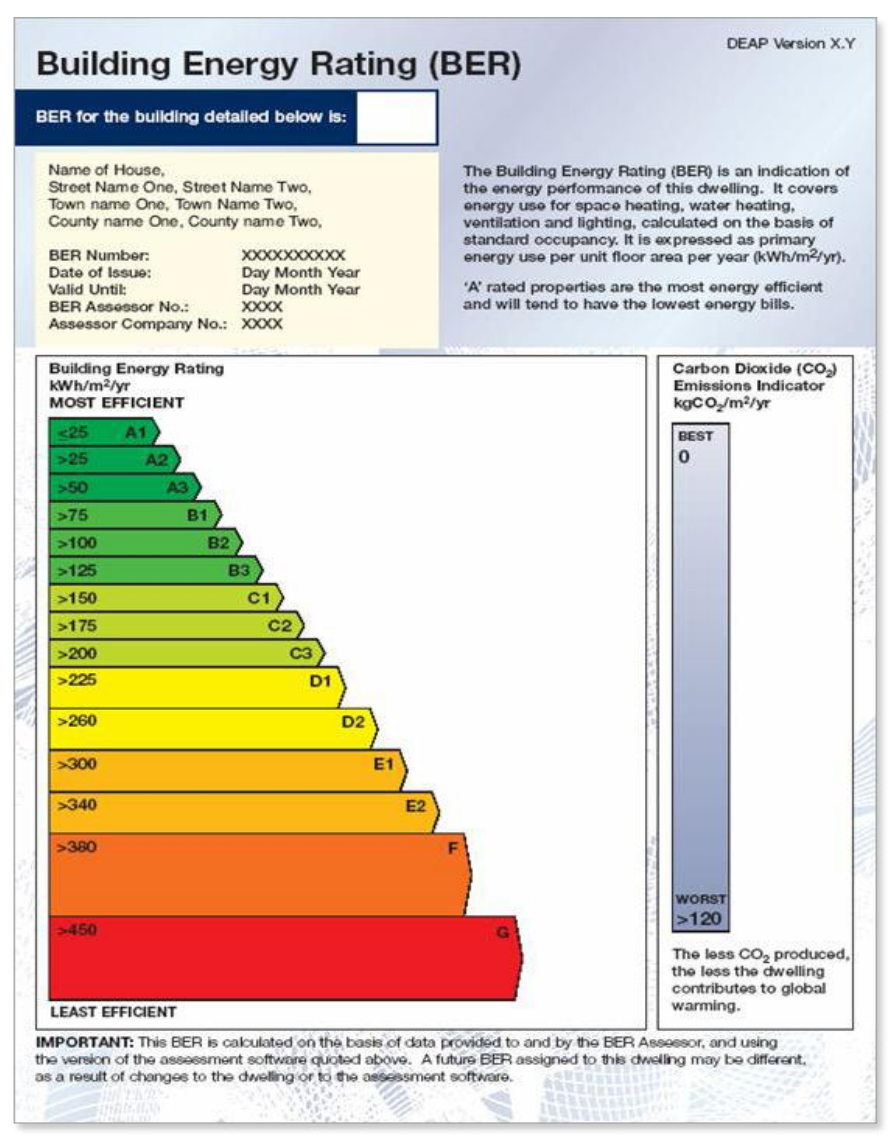

Fig. 1. Building Energy Rating Scale

(Source: http://www.ber.ie/images/chart.png)

The measured/operational rating can provide better information on a building's energy rating as it is not based on calculation but measurement of the energy used in a building. It is also more appropriate to use for building energy certificates.

The Ratings can be used while selling, renting, comparing, regulating or retrofitting, certificating or/and optimizing. The draft prEN 15203/15315 states that "because of the differences in the way these two ratings are obtained, they cannot be compared directly. However, the difference between the two ratings for the same building can be used to assess the cumulative effects of actual construction, systems and operating conditions versus standard ones and the contribution of energy uses not included in the calculated energy rating" [5].

Although it is not the concern of this article, energy efficiency rating and environmental impact rating are also worth mentioning. Energy efficiency rating is calculated according to the cost of energy use for each square meter floor area where environmental impact rating is calculated according to the carbon dioxide emission for the same unit area. The figures 2 and 3 below show samples of energy efficiency and environmental impact ratings for England and Wales.

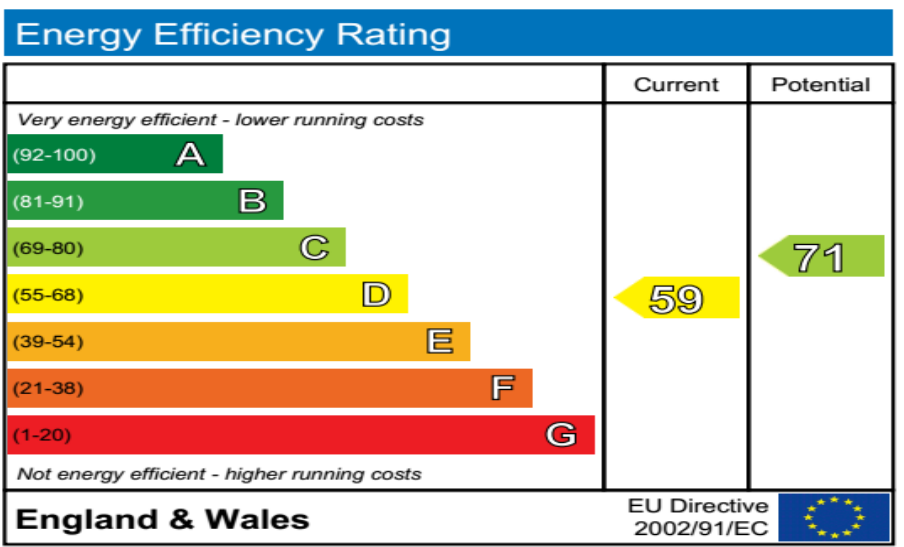

Fig. 2. Energy Efficiency Rating

(Source: http://www.energykey.co.uk/epcsample.pdf)

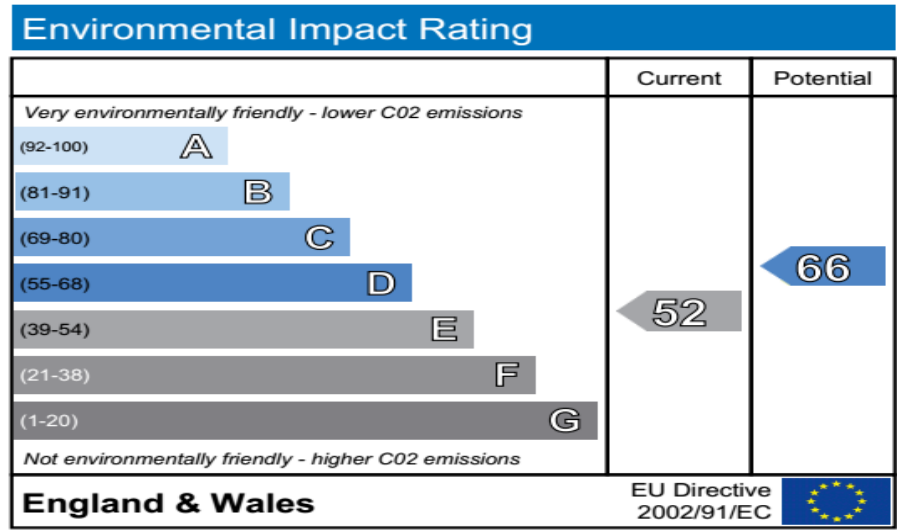

Fig. 3. Environmental Impact Rating

(Source: http://www.energykey.co.uk/epcsample.pdf)

\section{BUILDING ENERGY (PERFORMANCE) REGULATIONS AND CERTIFICATES}

According to The European Commission's official website [6], buildings in European Union consume $40 \%$ of total energy consumption and reason for $36 \%$ of $\mathrm{CO}_{2}$ emissions. It also states that buildings over 50 years old sum up $35 \%$ of all the buildings and old buildings use $25 \mathrm{lt}$ oil a year on average while recently built ones' average is less than 5 lt of oil a year. These figures show that energy conservation and environmental issues are significant enough to deal with international legislations while individual and organizational efforts are crucial as well. In addition, a study carried out by Texas A\&M indicated that $80 \%$ of the energy savings are from building tune-up [7].

Inevitably, The European Union set forward the 2010 Energy Performance of Buildings Directive as milestone legislation to lessen building energy consumption. The directive [6] states that;

- Building rental and sale advertisements are to include energy performance certificates

- Systems inspection schemes for heating and air conditioning are to be established in EU countries

- All new public and private buildings by 31 December 2018 are to be nearly zero energy buildings

- EU countries are to set minimum energy performance requirements for new buildings, for the major renovation of 
buildings and for the replacement or retrofit of building elements (heating and cooling systems, roofs, walls, etc.)

- EU countries are to draw up lists of national financial measures to improve the energy efficiency of buildings

Another important legislation on building energy consumption is the 2012 Energy Efficiency Directive. The directive [6] includes the following;

- EU countries make energy efficient renovations to at least 3\% of buildings owned and occupied by central government

- EU governments should only purchase buildings which are highly energy efficient

- EU countries must draw-up long-term national building renovation strategies which can be included in their National Energy Efficiency Action Plans

The European Union aims to cut its domestic greenhouse gas emissions by $80 \%$ by 2050 [8]. Previously, the Renewable Energy Directive ordered Member States to require minimum levels of energy from renewable sources in buildings by 31 December 2014 by stating "By 31 December 2014, Member States shall, in their building regulations and codes or by other means with equivalent effect, where appropriate, require the use of minimum levels of energy from renewable sources in new buildings and in existing buildings that are subject to major renovation. Member States shall permit those minimum levels to be fulfilled, inter alia, through district heating and cooling produced using a significant proportion of renewable energy sources. The requirements of the first subparagraph shall apply to the armed forces, only to the extent that its application does not cause any conflict with the nature and primary aim of the activities of the armed forces and with the exception of material used exclusively for military purposes." [9].

Directive 2002/91/EC [10] of the European Parliament and of the Council on the energy performance of buildings declares new and existing buildings as subject to energy certification.

Energy performance certificates are used to rate all types and sizes of buildings from the point of their energy performance/efficiency within proper users' comfort and buildings' functionality. Except for the mentioned primary function, they can be also used for recommendation purposes on upgrading a building and its payback while improving efficiency, users' comfort and saving money and environment.

Since different variables such as equipment, climate, building design and construction, energy and water systems are used in the certification process, building energy performance assessment should be carried out by a proficient evaluator / assessor. While doing so, building codes that refer to standards should be taken into account. For the new buildings under construction, certification is done to see whether the building meets the requirements of building codes whereas for the already existing buildings, it is used to compare them with the buildings alike and evaluate energy saving opportunities as Home Energy Rating System (HERS) Index does in USA. Energy performance certificates for existing buildings can be demanded while purchasing or renting. The European Union Energy Performance of Buildings Directory (EPBD) requires it even when advertising buildings and energy performance certificates cannot cover a longer period than ten years [4].
Another use of certificates is to allow building owners and prospective buyers to estimate the functionality of the building in comparison with others by using building energy codes from the point of energy efficiency. Similar to electrical gadgets, energy certificates also use an A to G labelling system in the European Union while HERS is used in USA [4]. For instance, a $\mathrm{C}$ label building which can be an average building means that there is still a lot of progress to be carried out while labelling moves from A to A++ to describe highly efficient buildings. Affirmative/positive labels mostly demand to meet the bottom prerequisites of standards. However, unfortunately, "the inclusion of recently adopted eco-design and labelling policies in the policy scenarios did not show any significant changes in energy consumption." [11]

Building certificates can be mandatory such as Energy Performance of Buildings Directory (EPBD) in The European Union or voluntary such as Energy star in USA. While voluntary certification is mostly applied by the owners of highly energy efficient buildings, mandatory ones are used to find the least energy efficient buildings among many others to recommend energy efficiency measurements. Because they are applied to a large number of buildings, mandatory certifications provide more information on buildings in general although they are more difficult to apply and consequently cost more. Yet, mandatory energy certificates may help governments to imply more realistic energy policies and lessen energy consumption and $\mathrm{CO}_{2}$ emission. The success of certification does not only depend on providing it but also following the procedures taken afterwards such as empowering procedures and proper systems, training the responsible and sustaining the required functions and qualities.

In the European Union, The Energy Performance of Buildings Directive (EPBD), The Directive 2002/91/EC, approved in 2003, builds the basics for energy efficiency in Europe. Dijk [12] summarizes the targets of the directory to improve buildings' energy efficiency, consequently performance in Europe as;

- Building a calculation methodology framework of building energy performance

- Applying minimum energy performance requirements for new buildings

- Providing building energy performance certificates

- Checking air-conditioning and boiler system systematically

- Setting standards for certification specialists and inspectors.

Mandatory building ratings and labelling are carried out by Energy Star in USA and by The European Energy Performance of Buildings Directive in EU. Although the EPBD provides a mandatory certification, members of the Union are free to choose the most appropriate procedures that fit themselves [12]. The common point in all systems are that they use benchmarking as the key to evaluate the building energy performances and efficiencies making energy building benchmarking the initial step for building labelling [13].

In spite of all standards, and certifications of energy ratings and performance/efficiency, there are still other concerns to build the best practice. One of them is insufficient number of buildings that follow the directory. A research in England and Wales showed that only $1 / 3$ of the inspected buildings meet the 
requirements of the directory [14]. Furthermore, the English House Condition Survey (EHCS) showed that better energy rated houses frequently devour more energy than lower rated ones [15]. Kelly [16] recommends that financial inducements and behavioral approaches be employed to close the gap between optimum and real energy use that is called energy performance gap. Another measurement to close that gap has been taken as energy policies that will be imposed for all new buildings by the end of 2020 [17]. The main reasons behind the energy performance gap may vary as;
- The directory itself, possibly more notional that practical

- The updates in directory as already existing buildings cannot follow updates easily

- Problems caused by building design, construction and material

- Lack of qualified assessors and appliers

- Issues concerning modelling and methods

- Lack of effective energy policies

A sample energy certificate is given in Figure 4 below.

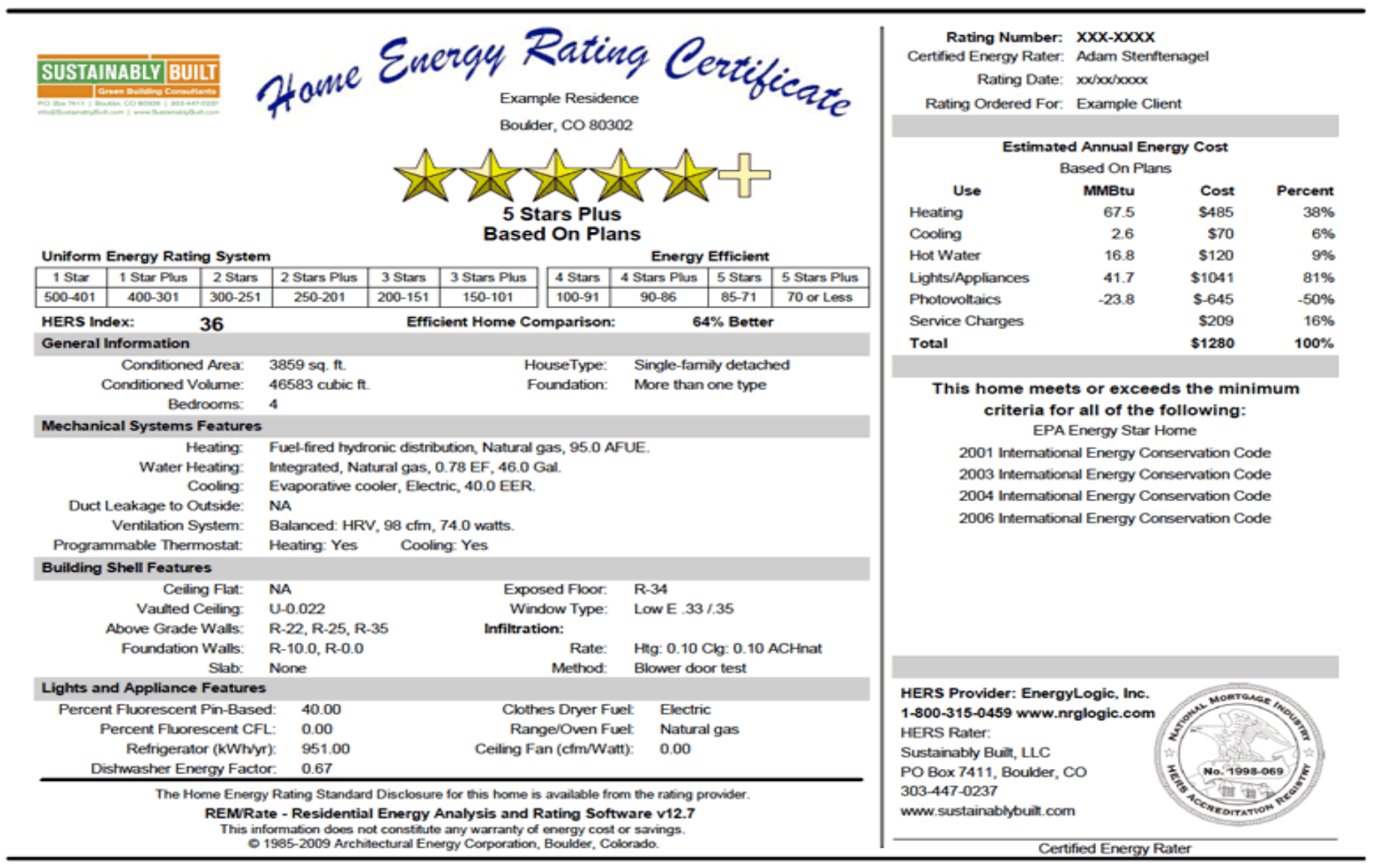

Fig. 4. Sample Home Energy Rating Certificate

(Source: http://sustainablybuilt.com/wp/wp-content/uploads/2013/09/HERC.gif)

\section{ENERGY BENCHMARKING}

Energy benchmarking in general and non-domestic buildings' energy benchmarking in specific are based on comparison between the target (building) and a successful sample one. It is considered "as one of the primary methods for improving energy efficiency and enabling transparency in energy consumption of buildings" [18]. The Construction Industry Institute (CII) defines benchmarking as "the systematic process of measuring one's performance against recognized leaders for the purpose of determining best practices that lead to superior performance when adapted and utilized" [19]. The break concerning the

present state of the subject building and the best practice building as a sample and benchmarking reference provides the target improvement. Depending on the type of organization and its objectives, benchmarking systems use precise indicators, such as cost, time or cycle time, productivity etc. per unit of measure [20].

The most common indicator to be used as benchmarking tool is $\mathrm{kWh} / \mathrm{m}^{2} /$ year. $\mathrm{CO}_{2} / \mathrm{m}^{2} /$ year as carbon emission and $\mathrm{kWh} /$ person/year as thermal comfort are also used. Choosing the right objectives and measures determined by success factors are vital for successful implementation [21]. Basic concepts in benchmarking are measurement, comparison and development prospects. Having found out what causes the inefficient performance in comparison with the best one in the market, measurements can be planned accordingly.

Benchmarking can be divided into two categories as internal and external. Internal benchmarking is mostly useful to compare operational processes with the desired ones when there is no external best practice sample. External one can be more fruitful to allow administrators to compare their progress and efficiency with their rivals to understand a more practical concept of what 
is considered as worthy. From another point of view, benchmarking can be sorted as;

- Process benchmarking that its business processes within their target with the best practice,

- Performance benchmarking that evaluates the organization's competitive place in comparison with the best practice in the market,

- Strategic benchmarking that searches how the best practices in other sectors work.

While considering benchmarking, organizations should first build a roadmap to follow. The following figure 5 by R.C. Camp [22] provides a sample benchmarking roadmap for organizations.

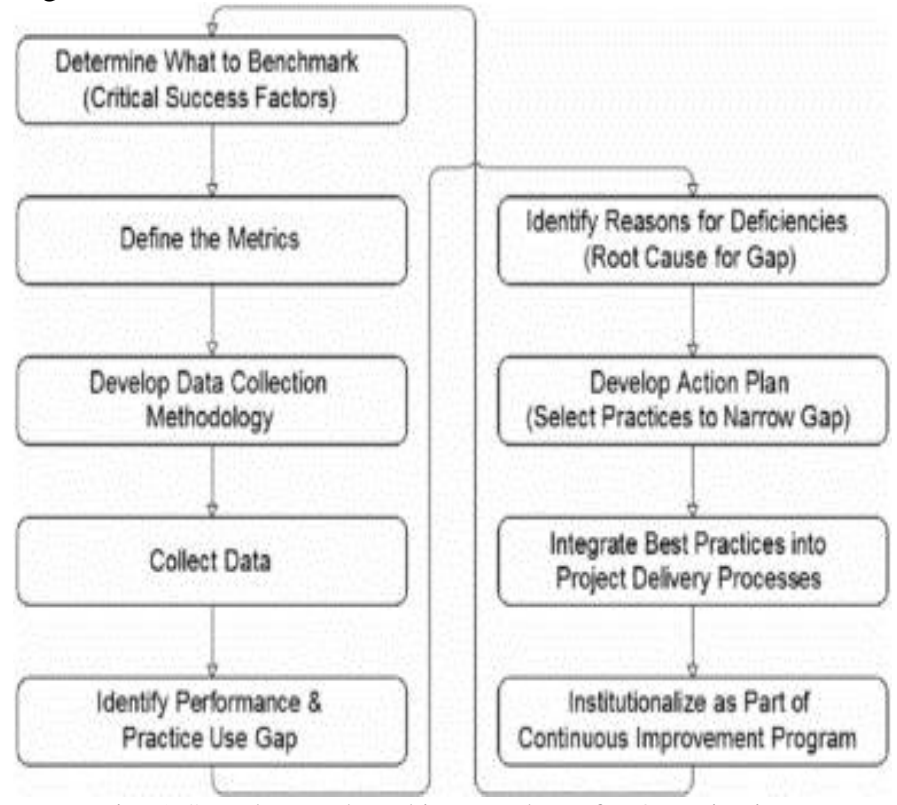

Fig. 5. Sample Benchmarking Roadmap for Organizations (Source: Camp, R.C., 1989. Benchmarking, The Search for Industry Best Practices That lead to Superior Performance. Portland, Ore.: ASQC Quality Press.)

A very important notion in benchmarking is that benchmarking should be taken as constant process at different levels starting from the construction rather than a random one. Another important issue for benchmarking is that improvement of the system is the backbone of the process rather than personal and sectional ones. One of the greatest, if not the greatest, obstacle in front of benchmarking is institutions' lack of awareness of the issue or/and lack of desire to implement it. For instance, benchmarking validation can be best achieved through the cooperation of an inside benchmarking unit, and an independent and qualified outside team. However, some organizations may resist to provide necessary information fearing that it will reveal their vital their inside information or weaknesses. On the other hand, readiness to compare and compete with the others encourages companies for benchmarking.

Various types of benchmarking methods can be used and Liddiard and Wright [23] provide the following list:

1) Ranking systems

2) Distribution models, using medians and percentiles

3) Regression models
4) Regression models using standard errors of a regression, or mean EUI (Energy Use Intensity),

5) Prototypical models

Differently, Borgstein and Lamberts [13] numerate building benchmarking methods as:

1) Simple normalization,

2) Stochastic frontier analysis that splits error variables from inefficiency factors

3) Data envelopment analysis that focuses on relative efficiency of a homogenous set of buildings.

4) Simulation of building performance that attempts to cultivate an archetypal model of the subject building.

The drawback of data development and simulation methods is that they cannot be used successfully as public benchmark. Stochastic frontier analyses are quite operative but their dependence on building features makes their implementation difficult.

When it comes to the relation between energy performance certificates (EPC) and benchmarking, calculated EPCs do not have any direct relation with benchmarking [24] as they are based on simulation and pre-calculation rather than comparison with the best practices. On the other side, benchmarking allows building owners/tenants to compare their process and performance in comparison with best practices of similar buildings under similar circumstances.

\section{ENERGY MANAGEMENT SOFTWARES (EMSs)}

Energy Management Softwares (EMSs) deliver energy use information for buildings including historic and real-time energy use, energy bills, energy system controls, carbon emission, energy audits, models and simulations. These softwares help to lower energy consumption and consequently energy bills. Data collection of EMSs is valuable to monitor and report the current situation and progress and engage necessary operations to reduce energy use.

Basically, real-time and historic energy consumption data from different sources are collected with intervals by using energy meters, sensors or automation programs or even energy bills. Intervals can differ from minute(s) to months and EMSs can collect information for any type of energy from renewable to electricity.

Although data collection is continual progress, reporting should be applied with some intervals as means of rating, benchmarking, comparing with previous data, similar organizations or national/international standards. A crucial point in data collection and reporting is that all the energy consuming appliances/sources, types of energy and means of energy use such as transportation, thermal heating and air conditioning should be aggregated to analyze where the energy goes and what precautions should be taken. Except from energy consumption data, other pieces of information such as weather, work shifts, space/area size and occupancy (density) can be also added to the energy management softwares to collect, analyze and report the collected data. The right data in the right time help to define organizations' energy performance/efficiency priorities.

EMSs may also help to find the gaps between the actual energy consumption and energy demand to work out the malfunction of the system or/and unplanned energy consuming 
function(s). Monitoring by tracing historical and real-time energy consumption data, and analyzing trends can help to spot opportunities to conserve energy. EMSs with benchmark tools and functions for modeling provide sufficient information to find out irregularities, peak energy use and faulty appliances and timers. One of the most important benefits of EMS monitoring is that the program sends warning messages if the pre-set energy values are exceeded. Engagement with automated or manual real-time displays enables both facility managers and users to respond energy flux in the building. For instance, energy peaks can activate appliance power-down function automatically. Engagement functions of EMSs also provide real-time energy consumption options, advice to save energy and an estimation of carbon emission of a facility. Only informing energy users about their real-time energy consumption can reduce it by $7 \%$ [25].

\section{V.CONCLUSION}

Building owner/tenants should get acquaintance with the standards and regulations to evaluate their building's energy performance and rating in accordance with (inter)national standards, compare with the best practices and obtain a certificate. The evaluation should be applied in regular intervals whereas the performance development process should be applied as a continuous one.

\section{ACKNOWLEDGMENT}

The author would like to express his gratitude to Prof. Dr. Shyqyri Llaci, Prof. Dr. Güngör Turan and Assist. Prof. Dr. Mustafa Üç for their guidance and support.

\section{REFERENCES}

[1] Directive 2010/31/EU of The European Parliament and of The Council of 19 May 2010 on the energy performance of buildings (recast), Official Journal of European Communities, L 153, 18.06.2010, pp. 1335.

[2] Energy performance of buildings. Overall energy use, CO2 emissions and definition of ratings, prEN 15603, European Committee for Standardisation, , Brussels, 2006, pp. 16.

[3] S.P Corgnati, S. Viazzo, and M. Filippi, "A method for heating consumption assessment in existing buildings: a field survey concerning 120 Italian schools". Energy and Buildings, vol. 40(5), pp. 801-809, 2008 .

http://dx.doi.org/10.1016/j.enbuild.2007.05.011

[4] IEA, Energy Performance Certification of Buildings. A policy tool to improve energy efficiency, 2010, pp. 12.

[5] CEN/BT WG173 - CEN TC228/WG4 N332_rev5, Energy performance of buildings - Overall energy use, $\mathrm{CO} 2$ emissions and definition of energy ratings, 2006, pp. 4.

[6] European Commission, Energy, Buildings. Available: https://ec.europa.eu/energy/en/topics/energy-efficiency/buildings (Accessed: October 13, 2015)

[7] Fish and Wildlife Service Energy Check List 2003 update, "Energy and Water Conservation". Professional Safety, , vol. 47(11), pp. 45, Nov 2002

[8] Z. Szalay and A. Zöld, "Definition of nearly zero-energy building requirements based on a large building sample", Energy Policy, vol. 74, pp. 510-521, November 2014.

[9] Directive 2009/28/EC of the European Parliament and of the Council of 23 April 2009 on the promotion of the use of energy from renewable sources and amending and subsequently repealing Directives 2001/77/EC and 2003/30/EC, Official Journal of the European Union, L 140/16 EN, pp. 18, 5.6.2009.

[10] Directive 2002/91/EC of the European Parliament and of the Council of 16 December 2002 on the energy performance of buildings, Official
Journal of European Union, L 001, pp. 0065-0071 (item 16), 04/01/2003.

[11] European Commission, Staff Working Document Impact Assessment, Accompanying the document Communication from the Commission to the European Parliament and the Council Energy Efficiency and its contribution to energy security and the 2030 Framework for climate and energy policy, Brussels, 23.7.2014 SWD (2014) 255 final PART 1/3, pp. 35.

[12] D. V. Dijk, Background, status and future of the CEN standards to support the Energy Performance of Buildings Directive (EPBD), Annexes to Report, TNO Built Environment and Geosciences Delft, The Netherlands, 2009, pp. 23.

[13] E. H. Borgstein, and R. Lamberts, R., "Developing energy consumption benchmarks for buildings: Bank branches in Brazil", Energy and Buildings, vol. 82, pp. 82-91, October 2014. http://dx.doi.org/10.1016/j.enbuild.2014.07.028

[14] W. Pan and H. Garmston, "Compliance with building energy regulations for new-build dwellings" Energy, vol. 48(1), pp. 11-22, December 2012. http://dx.doi.org/10.1016/j.energy.2012.06.048

[15] E. Burman, D. Mumovic, \& J. Kimpian, "Towards measurement and verification of energy performance under the framework of the European directive for energy performance of buildings", Energy, vol. 77, pp. 153163, December 2014. http://dx.doi.org/10.1016/j.energy.2014.05.102

[16] S. Kelly, "Do homes that are more energy efficient consume less energy?: a structural equation model of the English residential sector" Energy, vol. 36(9), pp. 5610-5620, September 2011. http://dx.doi.org/10.1016/j.energy.2011.07.009

[17] Directive 2010/31/EU of the European parliament and of the council of 19 May 2010 on the energy performance of buildings (recast), Official Journal of the European Communities, The European Parliament and the Council of the EU, L153/13-35, 18.06.2010.

[18] L. Pérez-Lombard, J. Ortiz, R. González, and I. R. Maestre, "A review of benchmarking, rating and labelling concepts within the framework of building energy certification schemes", Energy and Buildings, vol. 41(3), pp. 272-278, March 2009. http://dx.doi.org/10.1016/j.enbuild.2008.10.004

[19] Construction Industry Institute (CII), Construction Industry Institute Data Report, 1995, Austin, Tex.: Construction Industry Institute

[20] R. M. Fifer, "Cost benchmarking functions in the value chain", Strategy \& Leadership, vol. 17(3), pp. 18-19, December 1989. http://dx.doi.org/10.1108/eb054255

[21] R. S. Kaplan and D. P. Norton, The Balanced Scorecard. Boston, Mass.: Harvard Business School Press, 1996, pp. 148.

[22] R. C. Camp, Benchmarking, The Search for Industry Best Practices That Lead to Superior Performance, Portland, Ore.: ASQC Quality Press, 1989, pp. 35- 38.

[23] R. Liddiard, A. Wright, and L. Marjanovic-Halburd, A Review of NonDomestic Energy Benchmarks and Benchmarking Methodologies Institute of Energy and Sustainable Development, De Montfort University, Leicester, UK., 2008, pp. 130-136.

[24] L. Dias Pereira, H. Bernardo, and M. Gameiro da Silva, "Energy performance of school buildings: from Energy Certificates to Benchmarking, In: Climamed'13-VII Mediterranean Congress of Climatization-Istanbul", 3-4 October 2013, p. 511-519.

[25] Megatronicslab, "What is energy management?", Available: http://www.megatronicslab.com/ (Accessed: February 12, 2016) 